\title{
A FUZZY INVENTORY MODEL WITH LOT SIZE DEPENDENT ORDERING COST IN HEALTHCARE INDUSTRIES
}

\author{
R. Uthayakumar ${ }^{1}$ and S.K.Karuppasamy ${ }^{2 *}$ \\ ${ }^{1}$ Professor, Department of Mathematics, Gandhigram Rural Institute - Deemed University, \\ Gandhigram- 624302, Tamilnadu, India. \\ ${ }^{2}$ Research Scholar, Department of Mathematics, Gandhigram Rural Institute - Deemed \\ University, Gandhigram- 624 302, Tamilnadu, India.
}

\begin{abstract}
The classical Harris - Wilson inventory model assumes that all the cost associated with the model was taken to be constant and which does not dependent on any quantity ordered. In this paper we have taken Ordering cost, holding cost and order quantity all are triangular fuzzy numbers. Graded mean integration representation method is used for defuzzification. In this paper, we consider an inventory model where the ordering cost depends on the size of the lot and increases in steps as the lot size increases. The main goal of this research is to reduce the healthcare cost and without sacrificing customer service. An algorithm is developed to find the economic order quantity along with numerical examples in pharmaceutical company.
\end{abstract}

\section{KEYWORDS:}

Inventory, Lot size, Ordering Cost, Fuzzy inventory model, Triangular fuzzy numbers, Defuzzification.

Subject Classification Codes: $90 B 05$

$2^{2 *}$ Corresponding author Tel. +91-451-2452371, Fax: +91-451-2453071

\section{INTRODUCTION}

Kanti Swarup et al. [13] discussed about Inventory model, such as the basic of inventories. The total of an objects, a pharmaceutical company has in store at a particular time is known as inventory or in terms of money it can be defined as the total investment over all the resources stocked in the pharmaceutical company at any particular time. Inventory possibly in the type of, unprocessed material inventory, in process inventory, fulfilled goods inventory, etc.

As a lot of money is occupied in the inventories along with their high carrying costs, the pharmaceutical companies cannot afford to have any money tied in excess inventories. Any excessive investment in pharmaceutical inventories may prove to be a serious drag on the successful working of a healthcare organization. Therefore there is a must to deal with pharmaceutical inventories more successfully to free the excessive amount of capital engaged in the pharmaceutical materials. 
Inventory control is the supervision of supply, storage and accessibility of items in order to ensure an adequate supply without excessive oversupply. It can also be referred as internal control of an accounting procedure or system considered to promote good organization or assure the achievement of a policy or safeguards assets or avoid fraud and error, etc. In financial area, the inventory control problem, which plan to reduce overhead cost without hurting sales. In the field of loss anticipation, systems designed to introduce technical barriers to shoplifting. Also it answers the following basic questions of any supply chain: (1) what to order? (2)When to order? (3) Where to order? (4) How much to hold in stock? so as to increase finances.

In order to control inventories properly, one has to consider all cost elements that are linked with the inventories. There are few such cost essentials, which do affect cost of inventory. The total cost of holding inventory is called Carrying Inventory. This contain warehousing costs such as hire fee, utilities and salaries, financial costs such as opportunity cost, and inventory costs related to perishability, pilferage, reduction and assurance. Ordering cost is cost of ordering raw materials for pharmaceutical production purposes. These include cost of placing a purchase order, costs of check up of received batches, certification costs, etc.

Economic order quantity (EOQ) is the size of order which minimizes the total annual costs of carrying inventory and cost of ordering. Stock out cost is costs incurred when an item is out of stock. These costs include the lost contribution boundary on sales plus lost customer. The lead time is the time gap among placing of an order and its actual arrival in the pharmaceutical inventory. Demand is the number of units required per period. Demand refers to how much (quantity) of a manufactured goods or service is preferred by buyers at various prices.

One of the challenging problems for Healthcare researchers and practitioners is to study and analyze the inventory systems. Those systems cannot only decrease the costs, but also decrease stock outs and develop patient satisfactions. Medicine deficiencies and inappropriate use of pharmaceuticals can not only lead to economic losses but also have a considerable impact on patients. A lot of healthcare systems and hospitals familiarity difficulties in achieving these targets as they have not attend to how medicines are handled, supplied and used to save lives and develop health.

\section{LITERATURE REVIEW}

Inventory consists of usable but idle resources. There are many real life applications where this situation takes place. Let us consider an example that the freight costs which is required to be paid by the buyer. Usually the pharmaceuticals are shipped in a truck, train, van etc and when pharmaceuticals are received, they are checked, inspected because of the pharmaceuticals may be expired. If we use the expired one, we suffer lot. Therefore the ordering cost would in fact increase as the lot size increases.

The Harris - Wilson Formula [12] for determining the optimum lot size is the original and new model in the inventory systems. The Basic EOQ model considers three types of costs like cost of the product, ordering or set up cost and holding cost or carrying cost. A number of examiners deal with the modifications of these cost formations. It assumes that the ordering cost is constant and does not depend on the size of the lot. Vandana and B.K. Sharma [25], urbanized an inventory model for vendors partial permissible delay-in-payment connected to order quantity with deficiency, which is partial backlogged.

Gupta [11] thinks an inventory model wherever the ordering cost depends on the amount of the lot and rises in steps as the lot size rises. Gordon [10], Emery [8], Arrow [1] have given so many worth results in this field. A number of real locations carrying cost depends on the lot-size and different expansions of non-constant carrying cost can be seen in Beranek [2]. Karabi Dutta 
Choudhury et al [14] discussed about an inventory model with lot size dependent or carrying cost. Parvathi and Gajalakshmi [17] discussed a fuzzy inventory model with lot size dependent carrying or holding cost. The detailed study of basic concepts about fuzzy sets and fuzzy logic derived by George J. Klir/Bo Yuan [9].

Vandana and B.K. Sharma [23] discussed an EPQ inventory model for non-instantaneous deteriorating items under trade credit strategy also Vandana and B.K. Sharma [24] developed an inventory model for Non-Instantaneous deteriorating items with quadratic demand time and deficiencies under trade credit strategy.

Pharmaceuticals represent a considerable part of health care costs, account for around $10 \%$ of annual health care expenditure in the USA and about $\$ 600$ billion globally in 2009 [21]. R. Uthayakumar and S. Priyan [22], discussed for determining mainly positive solutions for inventory lot size, lead time, and the number of deliveries to achieve hospital Customer Service Level aims with a smallest total cost for the supply chain. J. K. Syed and L. A. Aziz [20] instead of the ordering cost and holding cost by fuzzy triangular number, the optimal order quantity is analyzed using Signed Distance Method for defuzzification.

Chien-Chang Chou [5] proposes a fuzzy backorder inventory model for solving the optimal order quantity inventory problem. Costs and quantities are uttered in trapezoidal fuzzy numbers. The Function Principle to utilize arithmetical process, the Graded Mean Integration Representation system to defuzzify, and the Kuhn-Tucker situations to find the best possible backorder amount and shortage amount for the fuzzy backorder amount inventory model.

V. N. Mishra [15] discussed some problems on approximations of functions in Banach Spaces. Deepmala and Das. A. K., [6] developed the existence, uniqueness, and iterative approximations of results for the functional equations arising in dynamic programming under Banach spaces and complete metric spaces.

Fuzzy sets in place of linguistic concepts such as low, medium, and high, are employed to define states of a variable. The membership function of a fuzzy set takes a quantity significance and may be sighted as a fuzzy number supplied they satisfy firm conditions. Fuzzy numbers are mostly applied on data analysis, artificial intelligence, and decision making. In particular, triangular fuzzy numbers are commonly used in applications and it is also easy to handle the difficulty. Thus the purpose of fuzzy set concepts on EOQ inventory models have been projected by many authors (e.g. $[3,4,7,16,18,26$, and 27]).

The remainder of the paper is organized as follows. Part 3 provides the notations and assumptions used. Source of the Operation Research model is described in part 4 and the solution process is obtainable in part 5. An efficient algorithm is urbanized to find the optimal solution in part 6 . A numerical example is provided in Section 7. Finally, we draw some conclusion in section 8.

\section{NOTATIONS AND ASSUMPTIONS}

We build up an Operation Research model using the notations and assumptions scheduled below. Further notations and assumptions are provided when necessary.

\subsection{Notations}

$\begin{array}{lll}\mathrm{D} & - & \text { Total / Annual Demand } \\ \mathrm{S} & - & \text { Setup Cost / Ordering Cost (per order) } \\ \mathrm{H} & - & \text { Holding Cost / Carrying Cost for a unit for one year. }\end{array}$


Operations Research and Applications : An International Journal (ORAJ), Vol.3, No.1, February 2016

Q

$\mathrm{TC}(\mathrm{Q})$
Order Quantity (in units) of the product

Minimum total inventory Cost of the product (in units)

\subsection{Assumptions}

- Demand is known and constant.

- Shortages are not allowed.

- The order quantity is received instantaneously.

- Lead time is zero.

- Ordering/Setup cost, holding/carrying cost and order quantity all are triangular fuzzy numbers

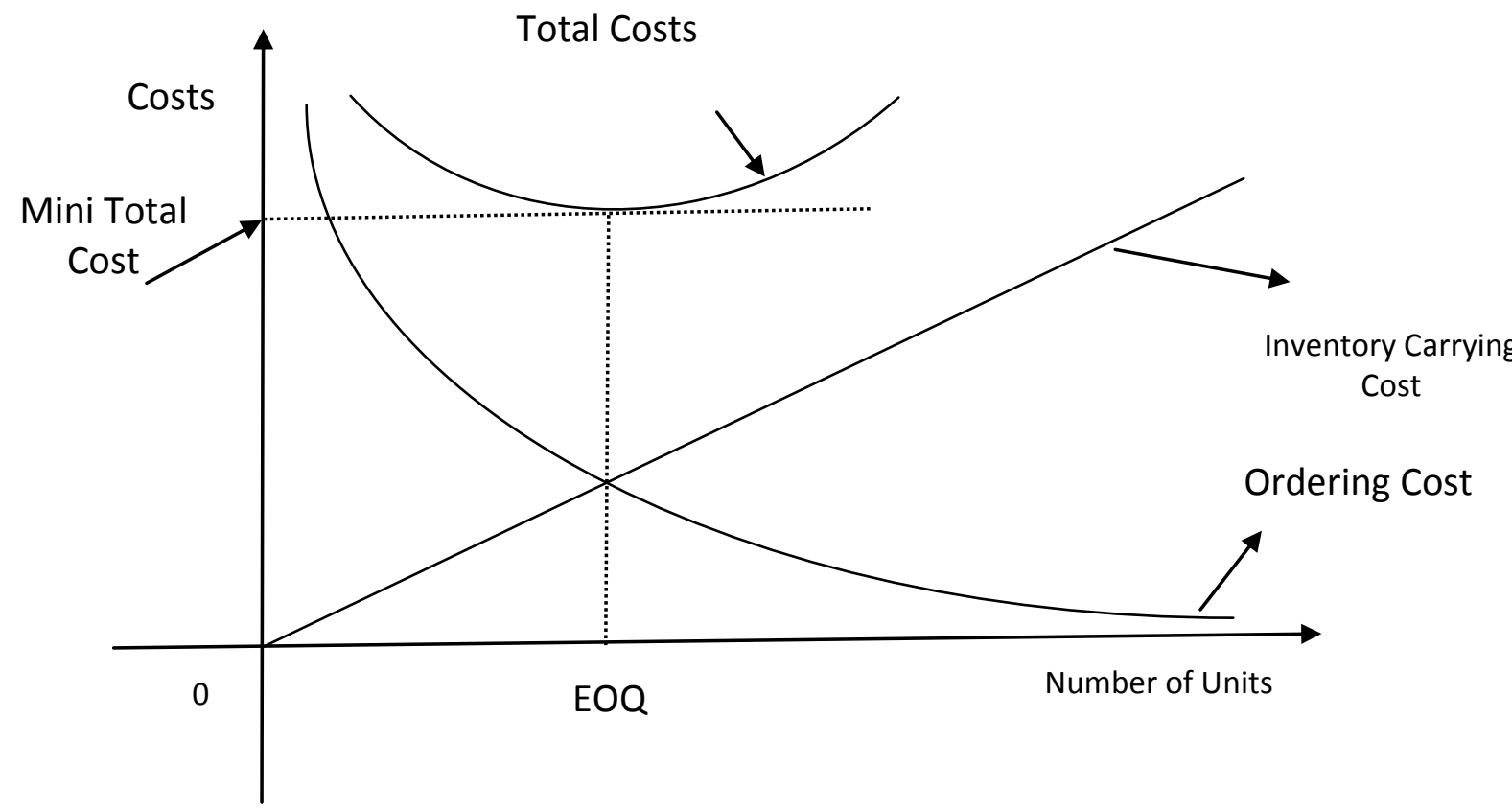

Figure 1. Graph of EOQ

\section{MATHEMATICAL MODEL FORMULATION}

The Harris Wilson technique for deciding the best possible lot size, the amount in which an article of inventory should be procured or constructs is $Q=\sqrt{\frac{2 * D * S}{H}}$

Our endeavor is to introduce additional realistic inventory model for which an algorithm is developed. Our planned model is illustrated through numerical examples.

This system follows that,

(1) The best possible amount reduces the sum of the annual setup/ordering cost and holding/carrying cost (figure 1) and

(2) The total cost is 


$$
T C(Q)=\frac{Q^{*} H}{2}+\frac{D^{*} S}{Q}
$$

i.e. the costs considered are understood to be unchanging. This body of research thinks that the factors concerned in the EOQ model, such as the demand and the purchasing cost are crisp values or random variables. However, in certainty, the demand and the cost of the pharmaceutical things often change slightly from one cycle to another. Also, it is very tough to estimate the probability distribution of these variables due to a need of historical data. Instead, the cost parameters are frequently estimated based on experience and individual healthcare management decision. Thus, the fuzzy set theory, rather than the conventional probability theory, is fine matched to the inventory.

The paper developed by Gupta considered the demand and holding costs as constant and ordering cost is non constant in their model. To generate it more realistic we have taken ordering/setup cost, holing/carrying cost and order quantity as triangular fuzzy numbers. Graded mean integration representation technique is used for defuzzification.

\section{Methodology}

\section{Fuzzy Numbers}

A fuzzy subset of the real line $R$, whose membership function $M_{f}$ satisfies the following situation, is a generalized fuzzy number $\tilde{A}$.

(i) $\mathrm{M}_{\mathrm{f}}$ is a continuous mapping from $\mathrm{R}$ to the closed interval [0,1],

(ii) $\mathrm{M}_{\mathrm{f}}=0,-\infty<x \leq a_{1}$

(iii) $\mathrm{M}_{\mathrm{f}}=\mathrm{L}(\mathrm{x})$ is strictly increasing on $\left[\mathrm{a}_{1}, \mathrm{a}_{2}\right]$

(iv) $\mathrm{M}_{\mathrm{f}}=\mathrm{W}_{\mathrm{A}}, a_{2} \leq x \leq a_{3}$

(v) $\mathrm{M}_{\mathrm{f}}=\mathrm{R}(\mathrm{x})$ is strictly decreasing on $\left[\mathrm{a}_{3}, \mathrm{a}_{4}\right]$

(vi) $\mathrm{M}_{\mathrm{f}}=0, a_{4} \leq x \leq \infty$

Where $0<\mathrm{W}_{\mathrm{A}} \leq 1$ and $\mathrm{a}_{1}, \mathrm{a}_{2}, \mathrm{a}_{3}$ and $\mathrm{a}_{4}$ are real numbers. Moreover, this kind of generalized fuzzy number is denoted as $\tilde{A}=\left(a_{1}, a_{2}, a_{3}, a_{4} ; W_{A}\right)_{L R}$; when $\mathrm{W}_{\mathrm{A}}=1$, it can be simplified as $\widetilde{A}=\left(a_{1}, a_{2}, a_{3}, a_{4} ; W_{A}\right)_{L R}$.

\section{The Triangular fuzzy number}

The fuzzy set $\tilde{A}=\left(a_{1}, a_{2}, a_{3}\right)$ where $\mathrm{a}_{1}<\mathrm{a}_{2}<\mathrm{a}_{3}$ and described on $\mathrm{R}$, is called the triangular fuzzy number, the membership function of $\tilde{A}$ is given by 
$M_{f}=\left\{\begin{array}{l}\frac{x-a_{1}}{a_{2}-a_{1}}, a_{1} \leq x \leq a_{2} \\ \frac{a_{3}-x}{a_{3}-a_{2}}, a_{2} \leq x \leq a_{3} \\ 0, \quad \text { Otherwise }\end{array}\right.$

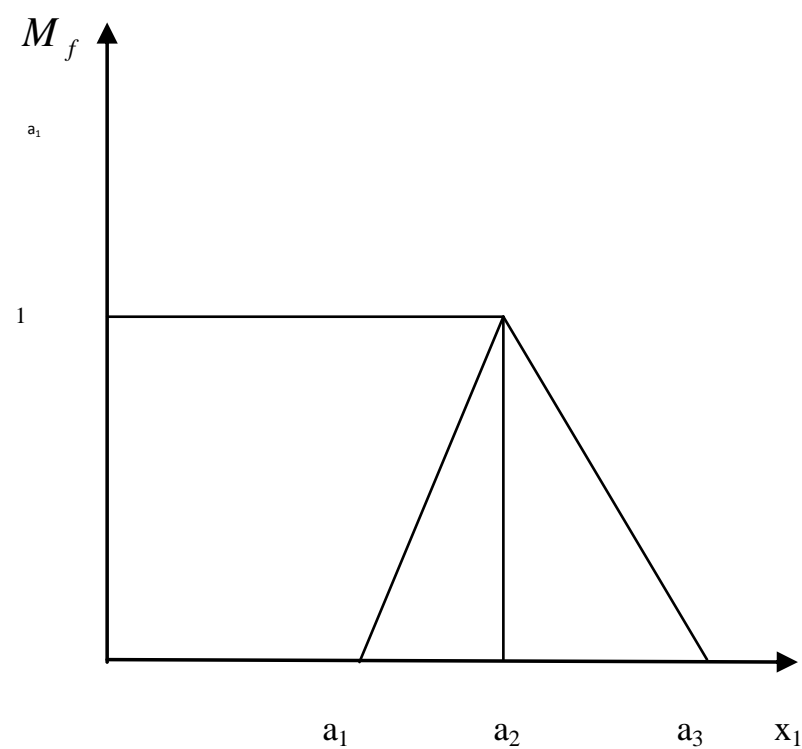

Figure 2. Triangular Fuzzy Number System

\section{The Function Principle}

The function principle was introduced by Shan-Huo Chen [19] to treat fuzzy arithmetical operations. This principle is used for the process for addition, subtraction, multiplication and division of fuzzy numbers.

Suppose $\tilde{A}=\left(a_{1}, a_{2}, a_{3}\right)$ and $\widetilde{B}=\left(b_{1}, b_{2}, b_{3}\right)$ are two triangular fuzzy numbers. Then

(i) the addition of $\widetilde{A}$ and $\widetilde{B}$ is

$\widetilde{A}+\widetilde{B}=\left(a_{1}+b_{1}, a_{2}+b_{2}, a_{3}+b_{3}\right)$ Where $\mathrm{a}_{1}, \mathrm{a}_{2}, \mathrm{a}_{3}, \mathrm{~b}_{1}, \mathrm{~b}_{2}, \mathrm{~b}_{3}$ are any real numbers.

(ii) The multiplication of $\tilde{A}$ and $\widetilde{B}$ is

$\tilde{A} \times \tilde{B}=\left(a_{1} b_{1}, a_{2} b_{2}, a_{3} b_{3}\right)$ Where $\mathrm{a}_{1}, \mathrm{a}_{2}, \mathrm{a}_{3}, \mathrm{~b}_{1}, \mathrm{~b}_{2}, \mathrm{~b}_{3}$ are all non zero positive real numbers.

(iii) $-\tilde{B}=\left(-b_{3},-b_{2},-b_{1}\right)$, the subtraction of $\tilde{B}$ from $\tilde{A}$ is

$\tilde{A}-\tilde{B}=\left(a_{1}-b_{3}, a_{2}-b_{2}, a_{3}-b_{1}\right)$ Where $\mathrm{a}_{1}, \mathrm{a}_{2}, \mathrm{a}_{3}, \mathrm{~b}_{1}, \mathrm{~b}_{2}, \mathrm{~b}_{3}$ are any real numbers. 
Operations Research and Applications : An International Journal (ORAJ), Vol.3, No.1, February 2016

(iv) $\frac{1}{\widetilde{B}}=\widetilde{B}^{-1}=\left(\frac{1}{b_{3}}, \frac{1}{b_{2}}, \frac{1}{b_{1}}\right)$ where $\mathrm{b}_{1}, \mathrm{~b}_{2}, \mathrm{~b}_{3}$ are all non zero positive real numbers, then the division of $\tilde{A}$ and $\widetilde{B}$ is $\frac{\tilde{A}}{\widetilde{B}}=\left(\frac{a_{1}}{b_{3}}, \frac{a_{2}}{b_{2}}, \frac{a_{3}}{b_{1}}\right)$

(v) For any real number $\mathrm{K}$,

$\mathrm{K} \widetilde{A}=\left(\mathrm{Ka}_{1}, \mathrm{Ka}_{2}, \mathrm{Ka}_{3}\right)$ if $\mathrm{K}>0$

$\mathrm{K} \tilde{A}=\left(\mathrm{Ka}_{3}, \mathrm{Ka}_{2}, \mathrm{Ka}_{1}\right)$ if $\mathrm{K}<0$

\section{Graded Mean Integration Representation Technique}

Defuzzification of $\tilde{A}$ can be done by Graded Mean Integration Representation Method. If $\tilde{A}$ is a triangular fuzzy number and is entirely determined by $\left(a_{1}, a_{2}, a_{3}\right)$ then defuzzified value is defined as

$$
G(A)=\frac{1}{2} \frac{\int_{0}^{1} h\left[a_{1}+h\left(a_{2}-a_{1}\right)+a_{3}-h\left(a_{3}-a_{2}\right)\right] d h}{\int_{0}^{1} h d h}=\frac{a_{1}+4 a_{2}+a_{3}}{6}
$$

\section{MATHEMATICAL MODEL DEVELOPMENT AND ANALYSIS}

In this model, we assume that the holding cost increases stepwise as the lot size increases. The following notations are used.

D - Total / Annual Demandv

$\tilde{H}$ - Fuzzy Holding cost per unit

$\tilde{S}_{j}$ - Setup cost / Ordering cost per order for the lot size $\tilde{Q}_{j}$ if $q_{j-i} \leq Q_{j} \leq q_{j}$

Where $\mathrm{j}=1,2,3 \ldots \mathrm{m} . q_{0}=0$ and $q_{\infty}=\infty$

Also assume $\mathrm{S}_{1}<\mathrm{S}_{2}<\mathrm{S}_{3}<\ldots \ldots . \mathrm{S}_{\mathrm{m}}$.

For ordering cost $\tilde{S}_{j}$ Harris - Wilson EOQ is given by

$$
\tilde{Q}_{j}=\sqrt{\frac{2 \times D \times \tilde{S}_{j}}{\tilde{H}}}
$$

If $\tilde{Q}_{j}$ does not lie in the interval $\left[\mathrm{q}_{\mathrm{j}-1}, \mathrm{q}_{\mathrm{j}}\right]$ i. e is not order possible, then the optimal lot size will be determined by

$$
\begin{array}{lll}
\mathrm{q}_{\mathrm{j}-1} & \text { if } & Q_{j} \leq q_{j-1} \\
\mathrm{q}_{\mathrm{j}} & \text { if } & Q_{j} \geq q_{j}
\end{array}
$$


Operations Research and Applications : An International Journal (ORAJ), Vol.3, No.1, February 2016

with the well-known value of $\tilde{Q}_{j}$ thus obtained from the equation (3), (4), and (5), $T \widetilde{C}\left(Q_{j}\right)$ can be calculated at the ordering cost by

$$
T \tilde{C}\left(Q_{j}\right)=\frac{\tilde{Q}_{j} \times \tilde{H}}{2}+\frac{D \times \tilde{S}_{j}}{\tilde{Q}_{j}}
$$

If $\tilde{Q}_{j}$ is order feasible then $T \tilde{C}\left(Q_{j}\right)$ will be the optimal cost, or else the value of $\tilde{Q}_{j}$ thus obtained by equations (4) and (5), is calculated by (6). Thus amongst all the calculated values of $T \tilde{C}\left(Q_{j}\right)$, the least rate will be the finest cost. After defuzzification of $\tilde{Q}_{j}$ and $T \tilde{C}\left(Q_{j}\right)$, we will get optimal $\mathrm{TC}\left(\mathrm{Q}_{\mathrm{opt}}\right)$ and the corresponding $\mathrm{Qj}$ will be the optimal lot size i.e $\mathrm{Q}_{\text {opt }}$.

\section{ALGORITHM}

1. Input $\mathrm{j}, \mathrm{n}=$ number of lot size.

2. $\quad$ Set $\mathrm{j}=1$.

3. Calculate $\tilde{Q}_{j}=\sqrt{\frac{2 \times D \times \tilde{S}_{j}}{\tilde{H}}}$

4. If $\tilde{Q}_{j}$ is order feasible,

5. Calculate $T \tilde{C}\left(Q_{j}\right)=\frac{\tilde{Q}_{j} \times \tilde{H}}{2}+\frac{D \times \tilde{S}_{j}}{\tilde{Q}_{j}}$. Go to Step 8 .

6. If $\tilde{Q}_{j}$ is not order feasible, afterward by equation (4) and (5), $\tilde{Q}_{j}$ can be calculated and hence find $T \tilde{C}\left(Q_{j}\right)$ by equation (6).

7. Set $\mathrm{j}=\mathrm{j}+1$, until $\mathrm{j}<=$ n. Go to step 3

8. Defuzzify $\widetilde{Q}_{j}$ as well as $T \tilde{C}\left(Q_{j}\right)$, subsequently we will get $\mathrm{Q}_{\mathrm{j}}$ and $\mathrm{TC}\left(\mathrm{Q}_{\mathrm{j}}\right)$.

9. Among all the calculated $\mathrm{TC}\left(\mathrm{Q}_{\mathrm{j}}\right)$, find the minimum value of $\mathrm{TC}\left(\mathrm{Q}_{\mathrm{j}}\right)$, and put $\mathrm{TC}\left(\mathrm{Q}_{\mathrm{opt}}\right)=$ $\min \left[\mathrm{TC}\left(\mathrm{Q}_{\mathrm{j}}\right)\right]$.

10. Thus TC $\left(Q_{\text {opt }}\right)$ obtained is the best possible cost and consequent $Q_{j}$ is the $Q_{\text {opt }}$ the optimal lot - size.

11. Thus $\mathrm{Q}_{\mathrm{opt}}$ and $\mathrm{TC}\left(\mathrm{Q}_{\mathrm{opt}}\right)$ are the necessary results. 
Operations Research and Applications : An International Journal (ORAJ), Vol.3, No.1, February 2016

\section{NUMERICAL EXAMPLES}

\section{Example 1}

We assume that the hospital need valuable medicines (Demand) from the pharmaceutical company and they spend money (holding cost) for that valuable medicines.

ie) $\mathrm{D}=10000$ units, $\tilde{H}=(180,190,200)$

\begin{tabular}{|c|c|c|c|c|c|c|c|}
\hline $\mathrm{J}$ & Range & $\tilde{S}_{j}$ & $\widetilde{Q}_{j}$ & $\mathrm{Q}_{\mathrm{j}}$ & $\begin{array}{c}\text { Feasible } \\
\tilde{Q}_{j}\end{array}$ & $T \tilde{C}\left(Q_{j}\right)$ & $\mathrm{TC}\left(\mathrm{Q}_{\mathrm{j}}\right)$ \\
\hline 1 & $01-30$ & $\begin{array}{c}(80,90, \\
100)\end{array}$ & $\begin{array}{c}(89.44,97.33, \\
105.41)\end{array}$ & 97.36 & 30 & $\begin{array}{l}(29367, \\
32850, \\
36333)\end{array}$ & 32850 \\
\hline 2 & $31-60$ & $\begin{array}{c}(90,100 \\
110)\end{array}$ & $\begin{array}{l}(94.87, \\
102.60 \\
110.55)\end{array}$ & 102.64 & 60 & $\begin{array}{l}(20400, \\
22367, \\
24333)\end{array}$ & 22367 \\
\hline 3 & $61-90$ & $\begin{array}{c}(100,110, \\
120)\end{array}$ & $\begin{array}{c}(100,107.61 \\
115.47)\end{array}$ & 107.65 & 90 & $\begin{array}{l}(19211, \\
20772, \\
22333)\end{array}$ & 20772 \\
\hline 4 & $91-120$ & $\begin{array}{c}(110,120, \\
130)\end{array}$ & $\begin{array}{l}(104.88, \\
112.39 \\
120.19)\end{array}$ & 112.44 & 112.44 & $\begin{array}{l}(19903, \\
21354, \\
22806)\end{array}$ & 21354 \\
\hline 5 & $121-150$ & $\begin{array}{c}(120,130, \\
140)\end{array}$ & $\begin{array}{l}(109.55 \\
116.98 \\
124.72)\end{array}$ & 117.03 & 121 & $\begin{array}{l}(20807, \\
22239, \\
23670)\end{array}$ & 22239 \\
\hline
\end{tabular}

Therefore, Optimal lot size $\mathrm{Q}_{\mathrm{opt}}=90$ units and the optimal total cost $\mathrm{TC}\left(\mathrm{Q}_{\mathrm{opt}}\right)=\mathrm{Rs.} 20772$. 
Operations Research and Applications : An International Journal (ORAJ), Vol.3, No.1, February 2016

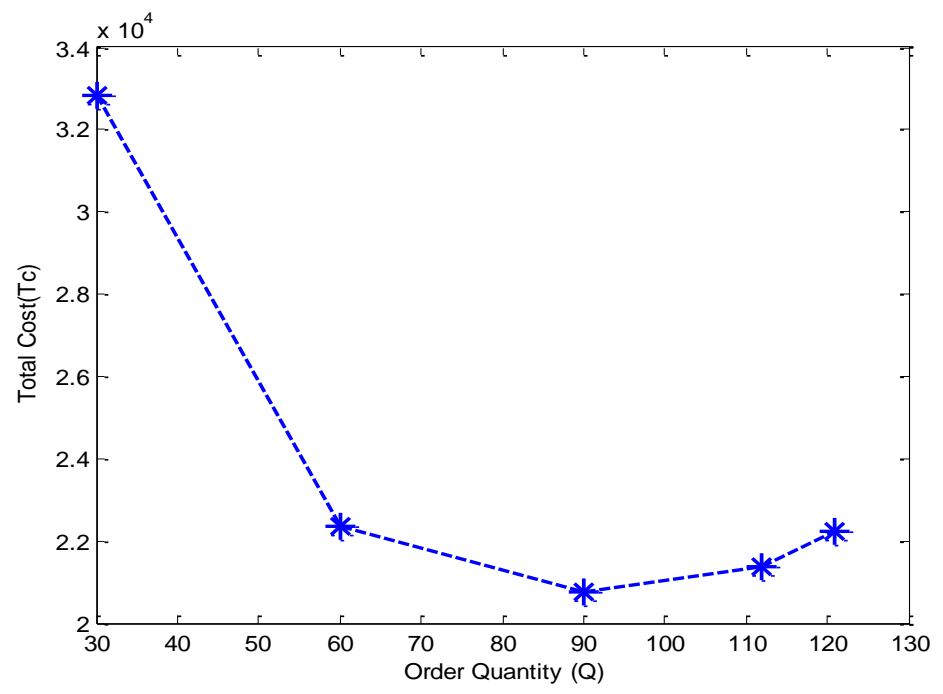

Figure 3. Graphical representation of optimal Solution for Example 1

\section{Example 2}

We assume that the hospital need valuable medicines (Demand) from the pharmaceutical company and they spend money (holding cost) for that valuable medicines.

ie) $\mathrm{D}=1000$ units, $\tilde{H}=(190,200,210)$

\begin{tabular}{|c|c|c|c|c|c|c|c|}
\hline $\mathrm{J}$ & Range & $\tilde{S}_{j}$ & $\tilde{Q}_{j}$ & $\mathrm{Q}_{\mathrm{j}}$ & $\begin{array}{c}\text { Feasible } \\
\tilde{Q}_{j}\end{array}$ & $T \widetilde{C}\left(Q_{j}\right)$ & $\mathrm{TC}\left(\mathrm{Q}_{\mathrm{j}}\right)$ \\
\hline 1 & $01-20$ & $\begin{array}{c}(90,100, \\
110)\end{array}$ & $\begin{array}{c}(29.28, \\
31.62,34.03)\end{array}$ & 31.63 & 20 & $\begin{array}{c}(6400,7000, \\
7600)\end{array}$ & 7000 \\
\hline 2 & $21-30$ & $\begin{array}{c}(100,110, \\
120)\end{array}$ & $\begin{array}{c}(30.86, \\
33.17,35.54)\end{array}$ & 33.18 & $\mathbf{3 0}$ & $\begin{array}{c}(6183,6667, \\
7150)\end{array}$ & $\mathbf{6 6 6 7}$ \\
\hline 3 & $31-40$ & $\begin{array}{c}(110,120, \\
130)\end{array}$ & $\begin{array}{c}(32.37, \\
34.64,36.99)\end{array}$ & 34.65 & 34.65 & $\begin{array}{c}(6466, \\
6928,7390)\end{array}$ & 6928 \\
\hline 4 & $41-50$ & $\begin{array}{c}(120,130, \\
140)\end{array}$ & $\begin{array}{c}(33.81, \\
36.06,38.39)\end{array}$ & 36.07 & 41 & $\begin{array}{c}(6822,7271, \\
7720)\end{array}$ & 7271 \\
\hline 5 & $51-60$ & $\begin{array}{c}(130,140, \\
150)\end{array}$ & $\begin{array}{c}(35.19, \\
37.42,39.74)\end{array}$ & 37.43 & 51 & $\begin{array}{c}(7394,7845, \\
8296)\end{array}$ & 7845 \\
\hline
\end{tabular}

Therefore lot size $\mathrm{Q}_{\text {opt }}=30$ units and the optimal total cost $\mathrm{TC}\left(\mathrm{Q}_{\mathrm{opt}}\right)=\mathrm{Rs.} 6667$. 


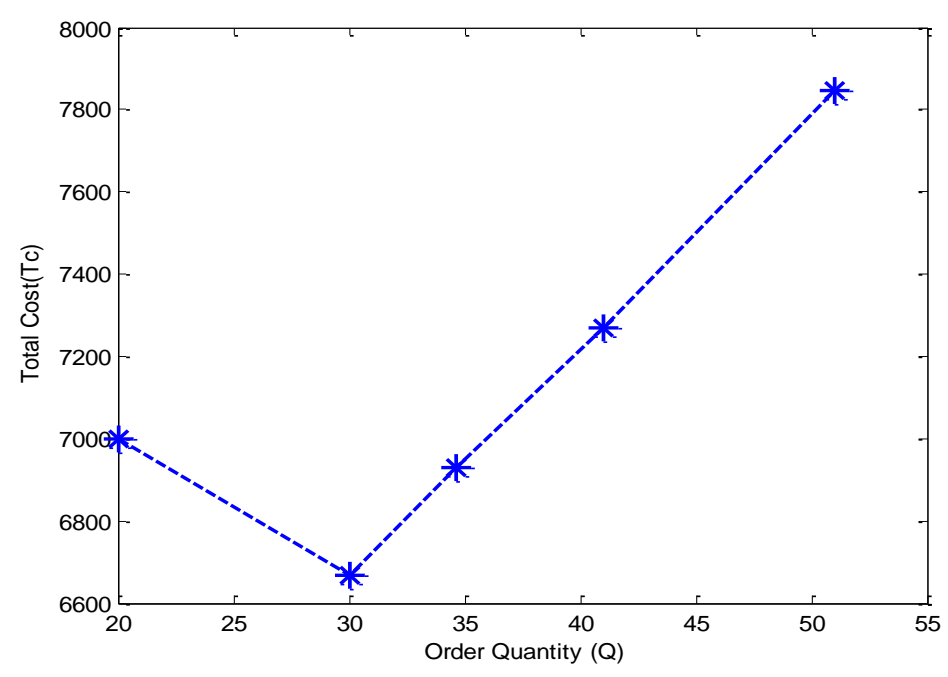

Figure 4. Graphical representation of optimal Solution for Example 2

\section{CONCLUSION}

In this article, the classical Harris - Wilson model has been extensive with fuzzy ordering cost depending on lot size. It is observed that if order quantity lies within the interval, it will give the best possible costs. Moreover if no such value can be obtained which is order feasible next we can build order feasible by equation (4) and (5). Since all the computed values of the least value will give the best possible ordering costs. We conclude that the best possible cost depends on demand required. The algorithm has been experienced with a numerical example. The results show that the algorithms described in this paper perform well.

We have measured fuzzy nature of ordering/setup cost, holding/carrying cost and order quantity. Even if the total cost in this model appears to be slightly higher than that in the standard model, this model is more suitable to real life situations.

\section{ACKNOWLEDGEMENTS}

The authors would like to thank anonymous referees for their most valuable, constructive, innovative comments and suggestions that have encouraged the authors to make significant improvements in this paper. This research is supported by the Council of Scientific and Industrial Research, Government of India under the Scheme of CSIR Research Project with CSIR/No. 25(0218)/13/EMR-II/Dated 05.09.2013. Department of Mathematics, Gandhigram Rural Institute - Deemed University, Gandhigram - 624302, Tamilnadu, India.

\section{REFERENCES}

[1] Arrow, K., Harris, T. and Marsc hak, J. (1951). Optimal Inventory Policy. Econometrica, Vol. 19, 250 $-272$.

[2] Beranek, W. (1967). Financial Implication of lot size inventory models. Management Science, Vol. 13.

[3] Bjork, K. M. (2009). An analytical solution to a fuzzy economic order quantity problem. The International Journal of Approximate Reasoning, Vol.50, 485-493.

[4] Chiang, J., Yao, J. S. and Lee, H. M. (2005). Fuzzy inventory with backorder defuzzification by signed distance method. Journal of Information Science and Engineering, Vol.21, 673-694. 
[5] Chien-Chang Chou (2009). A Fuzzy Backorder Inventory Model and Application to Determining the Optimal empty-container quantity at a port. International Journal of Innovative Computing, Information and Control, Vol. 5, 4825-4834.

[6] Deepmala and Das, A. K. On Solvability for Certain Functional Equations Arising in Dynamic Programming, Mathematics and Computing, Springer Proceedings in Mathematics \& Statistics, Volume 139 (2015), 79-94.

[7] Dutta, P., Chakraborty, D. and Roy, A. R. (2005). A single-period inventory model with fuzzy random variable demand. Mathematical and Computer Modelling, Vol.41, 915-922.

[8] Emery, J. C. (1954). Some theoretical aspect of inventory control, master's thesis in industrial management, M. I. T.

[9] George, J.Klir/ Bo Yuan (1995). Fuzzy Sets and Fuzzy Logic.

[10] Gordon, M. J. and Taylor, W. J. (1956). The condition for lot- size production. Journal of American Statistical Association, Vol. 51, 627-636

[11] Gupta, K. (1994). An inventory model with lot size dependent ordering cost Production planning and control. Vol. 6, 585-587.

[12] Harris, F. W. (1915). What quantity to make at once. The Library of Factory management, Vol. 5, Operations and Costa (A. W. Shaw Company, Chicago), 47-52.

[13] Kanti Swarup, Gupta, P. K. and Man Mohan (2009). Operation Research.

[14] Karabi Dutta, C., Sumit, S. and Mantu, D. (2011). An Inventory Model with Lot Size Dependent Carrying/Holding Cost. Assam University Journal of Science and Techonolgy, Physical Sciences and Technology, Vol. 7, 133-136

[15] Mishra, V. N. Some Problems on Approximations of Functions in Banach Spaces, Ph.D. Thesis (2007), Indian Institute of Technology, Roorkee - 247 667, Uttarakhand, India.

[16] Ouyang, L. Y. and Chang H. C. (2001). The variable lead time stochastic inventory model with a fuzzy backorder rate. Journal of the Operational Research Society, Japan, Vol. 44, 19-33.

[17] Parvathi, P. and Gajalakshmi, S. (2013). A Fuzzy Inventory Model with Lot Size Dependent Carrying Cost/ Holding Cost. IOSR Journal of Mathematics, Vol. 7, 106-110.

[18] Pu, P. M. and Liu, Y. M. (1980). Fuzzy topology 1, neighborhood structure of a fuzzy point and Moore-Smith convergence. Journal of Mathematical Analysis and Applications, Vol. 76, 571-599.

[19] Shan-Huo, C., (1996). Backorder fuzzy inventory model under function principle. Information Sciences, Vol. 95, 71-79.

[20] Syed J. K. and Aziz L. A. (2007). Fuzzy Inventory Model without Shortages Using Signed Distance Method. Applied Mathematics \& Information Sciences, Vol.1, 203-209.

[21] The Plunkett Research Group, (2010). Health Care Trends, http://www.plunkettresearch.com/Industries/HealthCare/HealthCareTrends/tabid/294/Default.aspx (accessed 10.05.2010).

[22] Uthayakumar, R. and Priyan, S. (2013). Pharmaceutical supply chain and inventory management strategies: Optimization for a pharmaceutical company and a hospital. Operations Research for Health Care, Vol. 2, 52-64.

[23] Vandana, Sharma, B.K. An EPQ inventory model for non-instantaneous deteriorating items under trade credit policy, International J. of Math. Sci. \&Engg. Appls. (IJMSEA), Vol. 9 No. I (2015), pp. 179-188.

[24] Vandana, Sharma, B.K. An inventory model for Non-Instantaneous deteriorating items with quadratic demand rate and shortages under trade credit policy, Journal of Applied Analysis and Computation (2015), in press.

[25] Vandana, Sharma, B.K. An EOQ model for retailers partial permissible delay in payment linked to order quantity with shortages, Mathematics and Computers in Simulation (2016), in press.

[26] Yao, J. S. and Wu, K., (2000). Ranking fuzzy numbers based on decomposition principle and signed distance, Fuzzy Sets and Systems, Vol. 116, 275-288.

[27] Yao, J. S. and Chiang, J. (2003). Inventory without backorder with fuzzy total cost and fuzzy storing cost defuzzified by centroid and signed distance. European Journal Operational Research, Vol. 148, 401-409. 


\section{AUTHORS}

R. Uthayakumar was born in Dindigul, Tamilnadu, India, in 1967. He received his B.Sc. degree in Mathematics from G.T.N. Arts College, Dindigul in 1987, M.Sc. degree in Mathematics from American College, Madurai in 1989, M.Phil., degree in Mathematics from Madurai Kamaraj University, Madurai in 1991, B.Ed. degree in Mathematics from Madurai Kamaraj University, Madurai in 1992 and Ph.D. degree in Mathematics from The Gandhigram Rural Institute - Deemed University, Gandhigram, India in 2000. Currently, he is professor of the Department of Mathematics at The Gandhigram Rural Institute - Deemed University, Gandhigram,

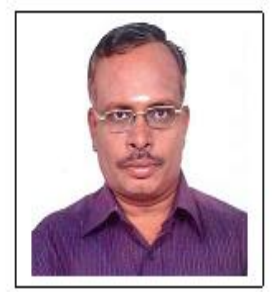
India. He has published about 157 papers in International and National journals. He is working as the Principal Investigator of the Major Research Project. One Research Projects Completed and Four Research Projects are ongoing. He is working as the Deputy Coordinator of Department Level Research Project. He is member of Scientific Bodies (Life member in the Ramanujan Mathematical Society), Board of studies, Board of Examiners and Question Paper Setters, Selection Committee and Inspection Committee. His research interests include the following fields: Mathematical Modeling, Fractal Analysis, Operations Research, Inventory Management \& Control and Supply Chain Management.

S.K. Karuppasamy is a full time research scholar in the Department of Mathematics at The Gandhigram Rural Institute - Deemed University, Gandhigram, India. He received his B.Sc degree in Mathematics from V.O.C. College, Tuticorin in 2003, M.Sc. degree in Mathematics from G.Venkataswamy Naidu College, Kovilpatti in 2005, M.Phil, degree in Mathematics from Madurai Kamaraj University, Madurai in 2006, and B.Ed. degree in Mathematics from Matha College, Manamadurai in 2007. He has 7 year of teaching experience. Currently, he is working as a Senior Research Fellow under CSIR Research Project, New Delhi, in the Department of Mathematics, The Gandhigram Rural Institute - Deemed University, Gandhigram, India. His research interests include

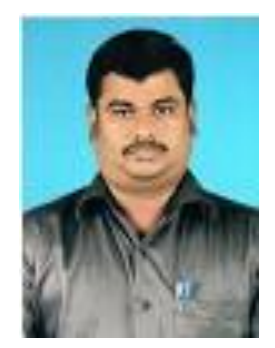
the following fields: operations research, inventory management and control, supply chain management. 